\section{Vagus nerve stimulation in chronic}

\section{treatment-resistant depression}

\author{
Preliminary findings of an open-label study \\ CIARAN D. CORCORAN, PHILIP THOMAS, JACK PHILLIPS \\ and VERONICA O'KEANE
}

\begin{abstract}
Summary We evaluated the efficacy and safety of vagus nerve stimulation therapy in the treatment of II patients with chronic treatment-resistant depression. Mood was evaluated at frequent intervals over the year following implantation. All measures of depression, including the Hamilton Rating Scale for Depression reduced significantly. The response and remission rates were $55 \%$ and $27 \%$ respectively at I year. Side-effects were common, and some were severe.
\end{abstract}

\section{Declaration of interest Cyberonics Incorporated, makers of the NeuroCybernetic Prosthesis system, sponsored this study.}

Major depressive disorder is one of the leading causes of morbidity in the world (Ustun et al, 2004). Chronicity, where there is ongoing unremitted major depression for at least a 2-year period, occurs in approximately $2.1 \%$ of the world population and is associated with severe impairment in psychosocial functioning (Scott, 2000). Vagus nerve stimulation therapy has been found to be an effective treatment for the management of resistant epilepsy and to be efficacious in some trials involving individuals with treatmentresistant depression (George et al, 2000). The aim of this study was to evaluate the safety and efficacy of vagus nerve stimulation therapy in 11 patients with chronic treatment-resistant depression.

\section{METHOD}

\section{Participants and setting}

Patients were recruited from Beaumont Hospital, Dublin. This centre was part of the European safety and efficacy study for vagus nerve stimulation therapy in treatment-resistant depression (D-03). Patients were eligible for inclusion if they fulfilled criteria for major depressive disorder, suffered from a chronic ( $>2$ years) current episode, scored $\geqslant 20$ on the Hamilton Rating Scale for Depression (HRSD; Hamilton, 1960) and had failed to respond to antidepressants from at least two different categories. Major depressive disorder was diagnosed using the Structured Clinical Interview for DSM-IV (First et al, 1996), and was measured using multiple scales including the HRSD and the Inventory of Depressive Symptomatology - Subjective Rating (Rush et al, 1986). Ethical approval was obtained locally. All patients gave fully informed written consent and were made aware of all potential complications.

\section{Surgical procedure}

The neurosurgical team, led by J.P. implanted the NeuroCybernetic Prosthesis system (Cyberonics Europe, Belgium) surgically. This procedure involves the subcutaneous implantation, under general anaesthetic, of a pacemaker-like device into the left axillary area of the chest, with a bipolar lead tracking from there to the cervical vagus nerve. The device operates by discharging a small fixed electrical signal of $30 \mathrm{~s}$ duration every $5 \mathrm{~min}$ to the vagus nerve.

\section{Study design}

There were two periods under study: an acute phase (12 weeks), commencing from 2 weeks after implantation, and a longterm phase of stimulation administration (40 weeks). For the first 2 weeks of the acute phase vagus stimulation was adjusted, and thereafter remained fixed until week 12. Participants were evaluated at weekly or 2-weekly intervals during this phase, and thereafter had follow-up evaluation at 6,9 and 12 months. A combined total of five antidepressants and mood stabilisers were allowed as long as the individual had been stable on these medications for 4 weeks before the initial visit. Patients were considered protocol violators if their antidepressant medications were changed during the acute phase. However, alterations in psychotropic medication were allowed during the long-term phase.

\section{Statistical analysis}

One-way analysis of variance of outcome measures over time was performed. Posthoc analysis was used to examine differences in scores over the specific time points. Response was defined as a $\geqslant 50 \%$ decrease in the HRSD from the baseline HRSD scores. Remission was defined as HRSD score $<10$.

\section{RESULTS}

All participants were White, with a mean age of 43 (s.d. $=8.72$ ) years, and $73 \%$ were female. Overall, patients had a long history of depression with a mean length of illness of 20 (s.d. $=8.34)$ years. They had a median episode duration of 46 months; only 2 had not had a previous episode. Electroconvulsive therapy (ECT) had been received by $55 \%$.

Table I Mean (s.d.) scores on Hamilton Rating Scale for Depression (HRSD-24), Montgomery-Åsberg Depression Rating Scale (MADRS) and Inventory of Depressive Symptomatology - Subjective Rating (IDS-SR) for II patients at 0, 3, 6 and I2 months after vagus nerve stimulation therapy

\begin{tabular}{lcccccc}
\hline Rating scale & Baseline & 3 months & 6 months & I year & $\begin{array}{c}\text { One-way ANOVA } \\
\text { F score (d.f.=40,3) }\end{array}$ & $P$ \\
& & & & & & \\
\hline HRSD-24 & $36.36(3.44) *$ & $28.27(8.52)$ & $29.73(8.83)^{*}$ & $19.27(12.74)$ & 6.70 & 0.001 \\
MADRS & $39.45(5.43)^{*}$ & $30.55(10.50)$ & $31.55(10.64)$ & $24.27(13.03)$ & 4.04 & 0.013 \\
IDS-SR & $57.81(8.44)^{*}$ & $43.73(13.53)$ & $41.45(15.67)$ & $31.81(19.41)$ & 5.78 & 0.002 \\
\hline
\end{tabular}

One-way analysis of variance (ANOVA) between the depression scores over the time points. ${ }^{*}$ Post-hoc $P<0.05$ compared with the score at 12 months. 


\section{Clinical outcomes}

All measures of depression were statistically reduced at 1 year compared with baseline (Table 1). There was one responder at 3 months, two responders at 6 months and 6 responders at 1 year. Three patients had remitted (defined as HRSD-24<10) by 1 year. Covarying for medications added during the study period did not result in any loss of statistical significance $(F(39,4)=6.5, P<0.001)$.

There were several serious adverse events. Patient 1 , a treatment non-responder, died by suicide at 9 months following implantation, but had not revealed this intention verbally. Patient 2 experienced a number of recurrences of pulmonary emboli that first occurred following surgery unrelated to the vagus nerve stimulation therapy. Patients 3 and 4 developed vocal cord palsies of mixed duration following surgery; the palsy of patient 3 lasted for approximately 2 months, and that of patient 4 approximately 6 months. There was a consequent delay in initiating treatment (i.e. the device was not switched on) until symptom resolution. Both patients made a full recovery from the palsy.

\section{DISCUSSION}

This study suggests that vagus nerve stimulation may be an effective treatment for some individuals suffering from chronic treatment-resistant depression. The response rates for the acute phase of the study were disappointing, in that only one patient responded after 3 months. By 1 year, 55\% of the sample had responded to treatment, suggesting that long-term follow-up is required to realise the therapeutic potential of vagus nerve stimulation treatment. The placebo response in these patients was typically poor and so probably does not account for the response rate (Stewart et al, 1993).

There was a striking number of adverse events in this study. It could be reasonably argued that the suicide was unrelated to the treatment, except insofar as treatment was ineffective, seeing that patient 1 left a suicide note explaining her intention before treatment to kill herself if the therapy did not cure her depression. It is more likely

CIARAN D. CORCORAN, MB, MRCPI, MRCPsych, Mental Health Unit, Royal Victoria Infirmary, Newcastle upon Tyne, UK; PHILIP THOMAS, MB, MRCSI, JACK PHILLIPS, MA, MB, MD, FRCSI, Beaumont Hospital, Dublin, Ireland; VERONICA O'KEANE, MB, PhD, MRCPI, FRCPsych, Institute of Psychiatry, King's College London, UK

Correspondence: Dr Ciaran Corcoran, Mental Health Unit, Leazes Wing, Royal Victoria Infirmary, Newcastle uponTyne NEI 4LP,UK. Email: ciaran.corcoran@ncl.ac.uk

(First received 26 October 2005, final revision 17 January 2006, accepted 31 January 2006)

that the pulmonary emboli that were experienced by patient 2 were related to her cancer or antipsychotic medication, rather than the vagus nerve stimulation. The vocal cord palsies experienced by patients 3 and 4 ( $18 \%$ of the sample) would appear to be an idiosyncratic finding: although this is a direct consequence of the surgical procedure, it usually only occurs in $1 \%$ of cases both internationally (George et al, 2000), and within the study hospital, where 50 such procedures are performed annually.

The findings from our trial are in keeping with previous observations of a response rate of $40 \%$ over a period of at least 1 year with vagus nerve stimulation treatment for major depressive disorder, suggesting that adequate time should be allowed before conclusions can be reached about clinical efficacy (Marangell et al, 2002).

Current physical treatment approaches to resistant depression include ECT (Folkerts et al, 1997) and psychosurgery (Bridges et al, 1994). ECT has a high incidence of reported adverse side-effects (UK ECT Review Group, 2003). Psychosurgery by its very nature will always be a treatment of last resort. It has been reported that $63 \%$ of patients receiving psychosurgery in the UK for resistant depression are markedly improved as a result (Royal College of Psychiatrists, 2002). Deep brain stimulation therapy has been reported to be effective in 4 out of 6 cases of resistant depression (Mayberg et al, 2005).

\section{Limitations}

The main limitations of this study were that it was an open study, and patients were not randomised to active or sham treatment. It was not possible for raters to be masked because of surgical scarring. In addition, the sample size was small. Medication changes were allowed during the long-term phase of the study, possibly impacting on the findings, although we controlled for this statistically.

\section{REFERENCES}

Bridges, P. K., Bartlett, J. R., Hale, A. S., et al (1994) Psychosurgery: stereotactic subcaudate tractomy. An indispensable treatment. British Journal of Psychiatry, $\mathbf{1 6 5}$ 599-611.

First, M. B., Spitzer, R. L., Gibbon, M., et al (1996) Structured Clinical Interview for DSM-IV Axis I Disorders, Clinician Version (SCID-CV). Washington, DC: American Psychiatric Press.

Folkerts, H.W., Michael, N., Tolle, R., et al (1997) Electroconvulsive therapy $v$. paroxetine in treatmentresistant depression - a randomized study. Acta Psychiatrica Scandinavica, 96, 334-342.

George, M. S., Sackeim, H. A., Rush, A. J., et al (2000) Vagus nerve stimulation: a new tool for brain research and therapy. Biological Psychiatry, 47, 287-295.

Hamilton, M. (1960) A rating scale for depression. Journal of Neurology, Neurosurgery and Psychiatry, 23, 56-62.

Marangell, L. B., Rush, A. J., George, M. S., et a (2002) Vagus nerve stimulation (VNS) for major depressive episodes: one year outcomes. Biological Psychiatry, 5I, 280-287.

Mayberg, H. S., Lozano, A. M., Voon, V., et al (2005) Deep brain stimulation for treatment-resistant depression. Neuron, 45, 65I-660.

Royal College of Psychiatrists (2002) Neurosurgery for Mental Disorder. Council Report CR89. London: Royal College of Psychiatrists.

Rush, A. J., Gilles, D. E., Schlesser, M. A., et al (1986) The Inventory for Depressive Symptomatology (IDS): preliminary findings. Psychiatry Research, 18, 65-87.

Scott, J. (2000) Treatment of chronic depression. New England Journal of Medicine, 20, 1518-1520.

Stewart, J. W., McGrath, P. J., Quitkin, F. M., et al (1993) Chronic depression response to placebo, imipramine and phenelzine. Journal of Clinical Psychopharmacology, 13, 391-396.

UK ECT Review Group (2003) Efficacy and safety of electroconvulsive therapy in depressive disorders: a systematic review and meta-analysis. Lancet, 36I, 799-808.

Ustun, T. B., Ayuso-Mateos, J. L., Chatterji, S., et al (2004) Global burden of depressive disorders in the year 2000. British Journal of Psychiatry, 184, 386-392. 